\title{
Classification of Evaluation Metrics for Project Baseline Schedules
}

\author{
Amr A. Wael, Ahmed Elyamany, Ahmed Elhakeem
}

\begin{abstract}
The Evaluation of construction baseline schedules aims to provide a high-quality project schedule. However, obtaining a project schedule free from technical defects remains a challenge to construction planners and schedulers.The result of having a high-quality schedule is achieving the desired project completion dates and avoid any disputes between the construction project parties which may be present due to the technical defects of the schedule itself. Many organizations and consultants had developed some evaluations techniques for assessing the baseline schedules from different prospects. The aim of this study is to classify and filter out the evaluation metrics and parameters of the project baseline schedule, in order to facilitate the schedule reviewing and evaluating process. This is achieved by introducing a clear, arranged and classified evaluation metrics to let the schedule reviewerto list down all the schedule technical defects and convert them into clear comments in order to rectify them and having a schedule free of defects.
\end{abstract}

Keywords: Baseline Evaluation, Baseline assessment, Schedule evaluation metrics.

\section{INTRODUCTION}

Construction planning is essential in managing and executing your construction projects as it involves defining the work tasks, estimating the required resources and extent of individual tasks, and identifying possible interactions and workflows among different activities. An efficient construction plan is fundamental in setting your budget and schedule for the entire work needed. Creating and developing the construction plan is a highly challenging and critical task in construction management. [1] There are many techniques for scheduling process. The most common scheduling techniques and methods are such as the Gantt charts, the Critical Path Method (CPM), the Program Evaluation and Review Technique (PERT) and the Line of balance. A Gantt chart is a horizontal bar chart developed as a production control tool in 1917 by Henry L. Gantt, an American engineer and social scientist. Frequently used in project management, a Gantt chart provides a graphical illustration of a schedule that helps to plan, coordinate, and track specific tasks in a project. Gantt charts are significant in the history of

Revised Manuscript Received on October 10, 2020.

* Correspondence Author

Amr A. Wael*, Department of Construction and Building Engineering, Arab Academy of Science and Technology, Cairo, Egypt.

Ahmed Elyamany, Construction Engineering Department, Zagazig University, (Currently at The British University in Egypt)., Cairo, Egypt.

Ahmed A. Elhakeem, Department of Construction and Building Engineering, Arab Academy of Science and Technology, Cairo, Egypt.

(C) The Authors. Published by Blue Eyes Intelligence Engineering and Sciences Publication (BEIESP). This is an open access article under the CC BY-NC-ND license (http://creativecommons.org/licenses/by-nc-nd/4.0/) modern project management, because theyrecognize the benefits of breaking large projects into smaller manageable tasks. They also account for the fact that some tasks may depend on each other. Gantt charts are still in use today and are considered a vital tool in a project manager's toolkit.[2]

Critical Path Method (CPM) is the most widely used scheduling technique and is often referred to as critical path scheduling. This scheduling technique used to plan and control a project and calculates the minimum completion time for a project along with the possible start and finish times for the project activities. The CPM was primary announced in 1958 as a cooperation between DuPont Corporation and Remington Rand Corporation.[3]

The Program Evaluation and Review Technique (PERT) is an assessment method which is used in evaluating and managing of uncertain activities construction projects. It is a network-based technique for planning and scheduling interrelated tasks in a project. Project managers use this methodology to optimize time and resources in large and complex projects. The PERT was developed for the U.S. Navy Special Projects Office in 1957 to support the U.S. Polaris nuclear submarine project.[4]

The Line of balance (LOB) is a management control process used in construction where the project contains blocks of repetitive work activities, such as roads, pipelines tunnels, railways and high raise building. LOB collects, measures and presents information relating to time, cost and completion and it present it against a specific plan. The LOB technique was created by the Goodyear Company in the early 1940s, before being adopted and developed by the U.S. Navy in the early-1950s.[5]

But as I mention before that the Critical path method (CPM) is the widely common technique, so that it is the technique which will be used in this research paper.

Schedule evaluation techniques had also many types depending on the purpose of the evaluation and the phase during which the evaluation was carried out or needed to be carried out throughout the life cycle of the construction project. These types of evaluation are;

- $\quad$ Evaluation of Baseline Schedule.

- Updated Schedule Evaluation.

- Delay Evaluation of Forensic Schedule.

The evaluation of baseline schedule usually occurs during the planning stage in the pre contract phase before starting with construction execution activities on the site. And also, as mentioned in the FIDIC general conditions, the contractor have to submit a baseline schedule for the project in order to be evaluated and approved officially by the employer and the engineer within 14 days from signing the contract agreement.

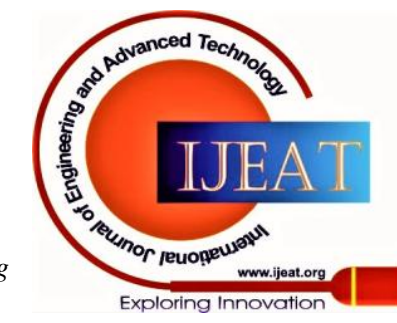


This type of evaluation is the most important type in order to meet the project's scope and dated milestones without any serious delays which may occur early in the project due technical defects in the baseline schedule. [6]

The updated schedule evaluation occurs after having the approval of the baseline schedule from the project's owner and the consultant. As per most contract clauses, the contractor must submit a weekly or monthly progress update report indicating the performance for the ongoing and completed activities executed on site. The actual work should be compared to the planned work approved by the consultant in the baseline schedule.[7]

The consultant must evaluate carefully these periodical narrative reports of the updated schedule and to ensure that this update is free from any defects, so as to give an actual status for the project for the project's owners and stakeholders.

According to Hoshino in 2011,Forensic schedule delay evaluation is usually occurred at a late stage from the construction life cycle. As it indicates a detailed schedule delay analysis which is commonly done by the engineer for official claims and disputes issues [8]. The essential aim of this evaluation is to show the actual effect of any serious delay done during the normal construction activities on site, and who is responsible for this delay in order to know if the contractor have a merit in an extension of time and/or cost or not. Usually this delay analysis is followed by a recovery plan in order to take the project status back on track with an actual and reasonable forecasted completion date.

The methods of schedule delay evaluation are:

- As-Built method,

- As-Planned vs. As-Built method,

- Window Analysis method,

- Time Impact Analysis.

The Evaluation of Baseline Schedule (EBS) is the one studied in this paper. EBS usually occurs during the pre-contract planning phase before starting construction on site. As required in most recent construction contracts, the contractor must submit a baseline schedule to be evaluated and officially approved by the employer and the engineer, within 7 to 14 days after signing the contract.[9]

The evaluation of the baseline schedule is a key indicator for the assessment of the schedule performance by reviewing its metrics. Many organizations developed their own guidelines and metrics for the evaluation of the baseline schedules. Some of these metrics are not be generalized. Other common metrics do not have any mutual criteria or reference which make them general and not specific with no numerical thresholds. So, these metrics and parameters need to be classified, filtered out and reviewed in order to be more specific and efficient.

\section{RESEARCH OBJECTIVES}

The objective of this study is to classify and filter out the available evaluation metrics of the project baseline schedules, and best recommended practices developed and published by construction organizations. This effort aims to facilitate the schedule reviewing and evaluating process by introducing a clear, arranged and classified evaluation metrics. The final chosen metrics will let the schedule reviewer to list down the technical defects of the schedule and convert them into clear recommendationthat could help the contractor to resolve these defects.

\section{PROPOSED CLASSIFICATION}

Here are the steps to achieve the study objectives of the proposed classification, as showed in Fig. 1:

First, the best recommended practices and guidebooks for evaluation, assessment and review of project schedules are thoroughly investigated and studied. Practices include evaluation metrics and parameters collected and recorded in a data sheet to be ready for filtering and classification. The amount of collected evaluation metrics add up to 76 metrics and parameters.

Second, thecollected evaluation metrics are filtered out using the following criteria:

- Select the quantitative metrices with numerical thresholds.

- Combine metrics common between different practices.

- Eliminates metrics related to detailed-levelschedules and updated schedule assessment during the constructionphase.

Third, classify filtered metricsinto metrics with exact thresholds and metrics with wide range thresholds.

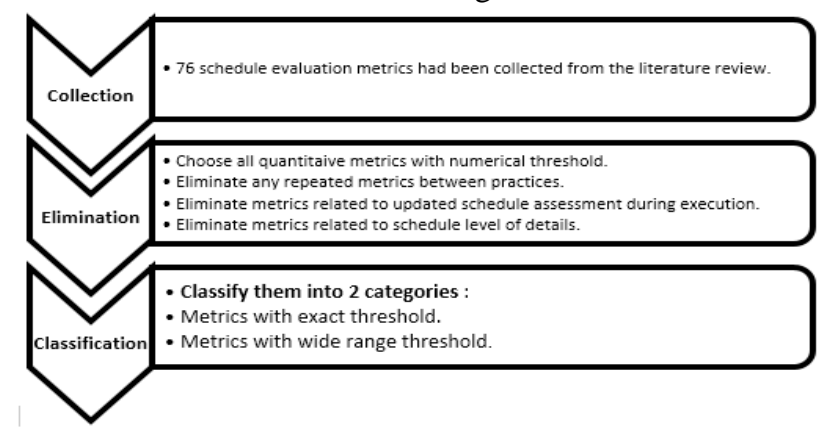

Fig.1. Methodology Steps

\section{DISCUSSION}

The best recommended practices for assessing, reviewing and evaluating the construction baseline schedules published by professional organizations, governments and researchers are listed below in Table 1

Table 1: Schedule Evaluation Recommended Practices

\begin{tabular}{|c|c|c|}
\hline No. & Organization & Published Guideline \\
\hline 1 & $\begin{array}{c}\text { U.S Government Accountability } \\
\text { Office (GAO) }\end{array}$ & Schedule Assessment Guide \\
\hline 2 & $\begin{array}{c}\text { Project Management Institute } \\
\text { (PMI) }\end{array}$ & $\begin{array}{c}\text { Practice Standard for } \\
\text { Scheduling }\end{array}$ \\
\hline 3 & $\begin{array}{c}\text { Defense Contract Management } \\
\text { Agency (DCMA) }\end{array}$ & $\begin{array}{c}\text { Earned Value Management } \\
\text { System (EVMS), Program } \\
\text { Analysis Pamphlet (PAP) }\end{array}$ \\
\hline 5 & $\begin{array}{c}\text { National Defense Industrial } \\
\text { Association (NDIA) }\end{array}$ & $\begin{array}{c}\text { Planning \& Scheduling } \\
\text { Excellence Guide (PASEG) }\end{array}$ \\
\hline 6 & $\begin{array}{c}\text { Andrew Avalon \& Curtis Foster } \\
\text { (AACE) }\end{array}$ & $\begin{array}{c}\text { Schedule Quality Assurance } \\
\text { Procedures }\end{array}$ \\
\hline
\end{tabular}

The Schedule Assessment Guide' published by the US. Government Accountability Office [10] defines recommended best practices for project baseline schedules which describes ten best practices to assist managers and planners with developing high quality and reasonable baseline schedule. These practices define practical steps and full description guidelines for creating the baseline schedule starting from capturing and sequencing all project's activities to maintain the baseline schedule.

Published By:
Eyes Intelligence Engineering and Sciences Publication

(C) Copyright: All rights reserved.

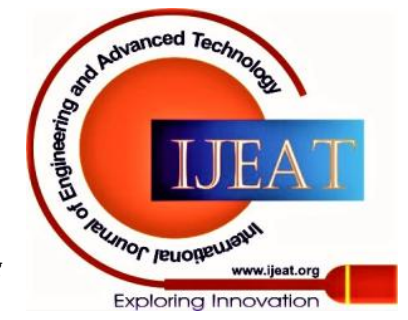


The US Defense Contract Management Agency [11] developed 14-points' assessments metrics in the "Earned Value Management System (2012)" in order to check the integration of the construction baseline schedule. The DCMA 14-points includes numerical thresholds for each assessment metric to evaluate whether it passes of fails. These assessment points define the development of schedule through numerical index for important factors of schedules such as (the number of activities without predecessor or successor, number of non-resourced activities, number of negative lags and hard constraints, and types of relationships). In addition to the index which are used to indicate the schedule performance as a final product such as the Critical Path Length Index (CPLI) and Baseline Execution Index (BEI) to measure the efficiency required to complete the project on-time and to measure the efficiency of the completed activities compared to the baseline planned activities in the same cut-off dates.

The National Defense Industrial Association [12], published "Planning and Scheduling Excellence Guide (PASEG)". This guide contains numerical metrics to help the planners and schedulers with practical methods for developing and maintaining construction schedules. It also contains 'Generally Accepted Scheduling Principles' (GASP) which explain ten-points of assessment that are developed in order to evaluate and control the quality of schedule and recommend further modification points to ensure the health of the schedule automated mechanism through the "The Schedule health assessment" presented by the (PASEG). Andrew Avalon \& Curtis Fosterin 2010 studied schedule procedure for a list of several review and analysis schedule metrics. The study the reviewer familiarity with the project scope as stated in the project documents such as: the project contract, drawings and specifications. Each project activities must be related to many work categories like engineering, procurements, construction, quality assurance and quality control. The developed practice contains 17 metrics and guidelines covering all schedule review process in order to help the reviewer to evaluate the baseline schedule.[13]

The Project Management Institute [14] developed the Practice Standard for Scheduling. The practice explains many techniques for planning and scheduling and consists of eight guidelines for developing the baseline schedules, each guideline describes a step or a precaution for creating the final project's schedule.

Naval Air Systems Command [15] had published and developed Integrated Master Schedule Guidebook (IMS). This practice is designed as a program management. This practice encompasses planning guides and quality standardsof baseline schedules.

The common parameters and metrics at least in 2 referencesof all publications that related to baseline schedule evaluation and assessment had been collected as shown in Table 2.

These metrics had been gathered with their descriptions, in order to integrate the same metrics with different names among all publications, as shown in Table 3.

\section{DATA AND RESULTS}

As mentioned before that all the data were collected from the literature review. About 76 guidelines and metrices had been collected from the best recommended practices related to the evaluation of construction schedules.

These metrics were filtered out and classified according to the criteria mentioned earlier in order to achieve the final desired parameters to be used later in developing a quantitative numerical evaluation technique for theconstruction baseline schedules.

Table 2: Schedule Evaluation Common Metrics

\begin{tabular}{|c|c|c|c|c|c|c|c|}
\hline \multirow{2}{*}{\multicolumn{2}{|c|}{ Common Metrics }} & \multirow{2}{*}{$\begin{array}{l}(1) \\
\text { GAO }\end{array}$} & \multirow{2}{*}{$\begin{array}{l}\text { (2) } \\
\text { PMI }\end{array}$} & \multirow{2}{*}{$\begin{array}{c}\text { (3) } \\
\text { DCMA }\end{array}$} & \multirow{2}{*}{$\begin{array}{c}(4) \\
\text { NDIA }\end{array}$} & \multirow{2}{*}{$\begin{array}{c}\text { (5) } \\
\text { AACE }\end{array}$} & \multirow{2}{*}{$\begin{array}{c}\text { (6) } \\
\text { NAVAIR }\end{array}$} \\
\hline & & & & & & & \\
\hline 1 & Scope & $\sqrt{ }$ & $\sqrt{ }$ & & & & \\
\hline 2 & Logic & $\sqrt{ }$ & $\sqrt{ }$ & $\sqrt{ }$ & $\sqrt{ }$ & & $\sqrt{ }$ \\
\hline 3 & Leads & & & $\sqrt{ }$ & $\sqrt{ }$ & & $\sqrt{ }$ \\
\hline 4 & Lags & & & $\sqrt{ }$ & & & $\sqrt{ }$ \\
\hline 5 & $\begin{array}{l}\text { Relationship } \\
\text { Types }\end{array}$ & & & $\sqrt{ }$ & $\sqrt{ }$ & & $\sqrt{ }$ \\
\hline 6 & $\begin{array}{l}\text { Hard } \\
\text { Constraints }\end{array}$ & & & $\sqrt{ }$ & $\sqrt{ }$ & $\sqrt{ }$ & $\sqrt{ }$ \\
\hline 7 & Float & $\sqrt{ }$ & & $\sqrt{ }$ & $\sqrt{ }$ & $\sqrt{ }$ & $\sqrt{ }$ \\
\hline 8 & $\begin{array}{l}\text { Negative } \\
\text { Float }\end{array}$ & & & $\sqrt{ }$ & $\sqrt{ }$ & & $\sqrt{ }$ \\
\hline 9 & Duration & $\sqrt{ }$ & $\sqrt{ }$ & $\sqrt{ }$ & $\sqrt{ }$ & $\sqrt{ }$ & $\sqrt{ }$ \\
\hline 10 & Invalid Dates & & & $\sqrt{ }$ & $\sqrt{ }$ & & $\sqrt{ }$ \\
\hline 11 & Resources & $\sqrt{ }$ & & $\sqrt{ }$ & $\sqrt{ }$ & $\sqrt{ }$ & $\sqrt{ }$ \\
\hline 12 & Missed Tasks & & & $\sqrt{ }$ & $\sqrt{ }$ & & $\sqrt{ }$ \\
\hline 13 & Critical Path & $\sqrt{ }$ & & $\sqrt{ }$ & & & $\sqrt{ }$ \\
\hline 14 & $\begin{array}{l}\text { Baseline } \\
\text { Execution } \\
\text { Index (BEI) }\end{array}$ & $\sqrt{ }$ & & $\sqrt{ }$ & & & $\sqrt{ }$ \\
\hline
\end{tabular}

Table 3: Schedule Evaluation Metrics Description

\begin{tabular}{|c|c|c|}
\hline \multicolumn{2}{|c|}{ Common Metrics } & Description \\
\hline 1 & Scope & $\begin{array}{l}\text { Capturing all activities related to project scope according to } \\
\text { the contract agreement. }\end{array}$ \\
\hline 2 & Logic & Sequencing all the activities in an appropriate logic network. \\
\hline 3 & Leads & Relationships with a negative lag duration. \\
\hline 4 & Lags & Relationships with a positive lag duration. \\
\hline 5 & $\begin{array}{l}\text { Relation } \\
\text { Types }\end{array}$ & The majority of the relationships should be finish to start. \\
\hline 6 & $\begin{array}{l}\text { Hard } \\
\text { Constraints }\end{array}$ & $\begin{array}{l}\text { Hard constraints must be used wisely and in limited way for } \\
\text { milestones. }\end{array}$ \\
\hline 7 & Float & Ensuring reasonable total float for the project. \\
\hline 8 & $\begin{array}{l}\text { Negative } \\
\text { Float }\end{array}$ & There should not be any negative float in the schedule \\
\hline 9 & Duration & $\begin{array}{l}\text { Establishing proper duration for all activities with suitable } \\
\text { level of details. }\end{array}$ \\
\hline 10 & Invalid Dates & There should not be any invalid dates in the schedule. \\
\hline 11 & Resources & $\begin{array}{l}\text { Activities with original duration must be assigned with } \\
\text { resources. }\end{array}$ \\
\hline 12 & Missed Tasks & $\begin{array}{l}\text { Tasks whose actual finish date is later than their earlier } \\
\text { planned finish date. }\end{array}$ \\
\hline 13 & Critical Path & Confirming the validity of the project critical path. \\
\hline 14 & $\begin{array}{l}\text { Baseline } \\
\text { Execution } \\
\text { Index (BEI) }\end{array}$ & $\begin{array}{l}\text { The ratio of all actual completed activities to the planned } \\
\text { completed activities till the data date. }\end{array}$ \\
\hline
\end{tabular}

After collecting all the metrics and parameters related to schedule assessment, filtering out and classification criteria had been applied on the data. And as a result, the selected data was classified into two categories: metrics with exact thresholds and metrics with wide range thresholds.

Table 4 shows the metrics with exact thresholds category which contains four metrics with exact thresholds; Leads (Negative Lags), Negative Float and Resource.

Table 5 shows the metrics with range thresholds category which include

fourrangethresholdsmetrics:logic, lags, relationships and har d constraints. Each matric and parameter has its own description with its numerical threshold of wide range as shown in

\section{Published By:}

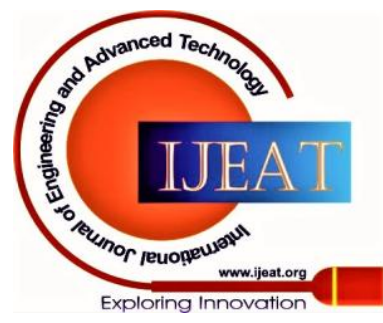




\section{Classification of Evaluation Metrics for Project Baseline Schedules}

Table 3. Since these chosen metrics will be the main frame of design of the model with its scope of acceptance as they reflect the technical quality of the schedule at the beginning of the project and impact the schedule output at the end of the project. These classified metrics will be used later in developing a model of a quantitative numerical evaluation technique for the construction baseline schedules

Table 4: Metrics with Exact Threshold

\begin{tabular}{|c|l|l|c|}
\hline$\#$ & \multicolumn{1}{|c|}{$\begin{array}{c}\text { Quantitative } \\
\text { Metrics }\end{array}$} & \multicolumn{1}{|c|}{ Description } & $\begin{array}{c}\text { Exact } \\
\text { Threshold }\end{array}$ \\
\hline 1 & Leads & $\begin{array}{l}\text { Percentage number of } \\
\text { relationships with negative lag } \\
\text { duration. }\end{array}$ & $\begin{array}{c}\text { Must be } \\
\text { Zero }\end{array}$ \\
\hline 2 & Negative Float & $\begin{array}{l}\text { Percentage number of activities } \\
\text { with negative float }\end{array}$ & $\begin{array}{c}\text { Must be } \\
\text { Zero }\end{array}$ \\
\hline 3 & Resources & $\begin{array}{l}\text { Percentage number of activities } \\
\text { with duration with missing not } \\
\text { assigned resources }\end{array}$ & $\begin{array}{c}\text { Must be } \\
\text { Zero }\end{array}$ \\
\hline
\end{tabular}

Table 5: Metrics with Range Threshold

\begin{tabular}{|c|l|l|c|}
\hline$\#$ & $\begin{array}{c}\text { Quantitative } \\
\text { Metrics }\end{array}$ & \multicolumn{1}{|c|}{ Description } & Threshold \\
\hline 1 & Logic & $\begin{array}{l}\text { Percentage number of } \\
\text { activities missing predecessors } \\
\text { or successors. }\end{array}$ & $\leq 5 \%$ \\
\hline 2 & Lags & $\begin{array}{l}\text { Percentage number of } \\
\text { relationships with a positive } \\
\text { lag duration. }\end{array}$ & $\leq 5 \%$ \\
\hline 3 & Relationships & $\begin{array}{l}\text { Percentage number of } \\
\text { relationships type not } \\
\text { Finish-to-Start }\end{array}$ & $\leq 10 \%$ \\
\hline 4 & $\begin{array}{l}\text { Hard } \\
\text { Constraints }\end{array}$ & $\begin{array}{l}\text { Percentage number of } \\
\text { activities with hard constraints. }\end{array}$ & $\leq 5 \%$ \\
\hline
\end{tabular}

\section{CASE STUDY}

A case study had been developed for an actual construction project schedule, in order to make a clear application for the output of this paper. The project encompasses a standalone villa, which is locatedin a residential compound in Egypt. The project's schedule parameters were extracted according to the chosen parameters and metrics in the research to develop the case study and calculated as shown in Table 6 .

Then the evaluation process will start with the first phase under a title of "Metrics with Exact Threshold" by comparing the project's schedule metrics with the thresholds assigned and see whether the metric is passed of failed. If failed, the reviewer will make comments in order to help the planner to achieve the metric value with the exact threshold as shown in Table 7.

After that in phase 2 under a title of "Metrics with Range Threshold", the same process will be proceeded such as in phase 1 as shown in Table 8 .

At the end, the evaluation process had helped the reviewer to give the plannersome obvious comments for the metricswhich did not achieve the threshold margins. The planner must modify these comments and re-submit the baseline schedule with another revision to the reviewer in order to take the final approval on the schedule after rectifying all the defects and taking into consideration all the comments stated by the reviewer.
Table 6: Case Study Metrics

\begin{tabular}{|l|c|c|}
\hline \multicolumn{1}{|c|}{ Metrics } & Calculate & $\begin{array}{c}\text { Project } \\
\text { Metrics }\end{array}$ \\
\hline Leads & $\frac{\text { No. of Relationships with Leads }}{\text { Total of Relationships }} \times 100$ & $0 \%$ \\
\hline $\begin{array}{l}\text { Negative } \\
\text { Float }\end{array}$ & $\frac{\text { No. of Activities With Negative Float }}{\text { Total of Activities }} \times 100$ & $0 \%$ \\
\hline Resources & $\frac{\text { No. of Act. With Missing Resources }}{\text { Total of Activities }} \times 100$ & $7 \%$ \\
\hline Logic & $\frac{\text { No. of Act. Without Pred. and/or Suc. }}{\text { Total of Activities }} \mathbf{1 0 0}$ & 1.02 \\
\hline Lags & $\frac{\text { No. of Relationships with Lags }}{\text { Total of Relationships }} \times 100$ & 5.3 \\
\hline Relationships & $\frac{\text { No. of Finish to Start Relationships }}{\text { Total of Relationships }} \boldsymbol{x} 100$ & 56.1 \\
\hline $\begin{array}{l}\text { Hard } \\
\text { Constraints }\end{array}$ & $\frac{\text { No. of Activities With Hard Constraints }}{\text { Total of Activities }} \times 100$ & 0.12 \\
\hline
\end{tabular}

Table 7 Case Study Metrics with Exact Thresholds

\begin{tabular}{|l|c|c|c|c|}
\hline \multicolumn{5}{|c|}{ Phase 1: Metrics with Exact Thresholds } \\
\hline Metrics & $\begin{array}{c}\text { Project } \\
\text { Metrics }\end{array}$ & Threshold & Status & Comments \\
\hline Leads & $0 \%$ & $\begin{array}{c}\text { Must be } \\
\text { Zero }\end{array}$ & Pass & \\
\hline $\begin{array}{l}\text { Negative } \\
\text { Float }\end{array}$ & $0 \%$ & $\begin{array}{c}\text { Must be } \\
\text { Zero }\end{array}$ & Pass & Fail \\
\hline Resources & $9 \%$ & $\begin{array}{c}\text { Must be } \\
\text { Zero } \\
\text { activities with } \\
\text { duration missing } \\
\text { resources must be } \\
\text { zero }\end{array}$ \\
\hline
\end{tabular}

Table 8 Case Study Metrics with Range Thresholds

\begin{tabular}{|l|c|c|c|c|}
\hline \multicolumn{5}{|c|}{ Phase 2: Metrics with Wide Range Thresholds } \\
\hline Metrics & $\begin{array}{c}\text { Project } \\
\text { Metrics }\end{array}$ & Threshold & Status & Comments \\
\hline Logic & 1.02 & $\leq 5 \%$ & Pass & \\
\hline Lags & 5.3 & $\leq 5 \%$ & Fail & $\begin{array}{c}\text { The number of } \\
\text { relationships } \\
\text { having lags must } \\
\text { be less than 5\% }\end{array}$ \\
\hline Relationships & 23.2 & $\leq 10 \%$ & Fail & $\begin{array}{c}\text { The number of } \\
\text { Finish-Start } \\
\text { relationships } \\
\text { must be greater } \\
\text { than 90\% }\end{array}$ \\
\hline $\begin{array}{l}\text { Hard } \\
\text { Constraints }\end{array}$ & 0.12 & $\leq 5 \%$ & Pass & \\
\hline
\end{tabular}

\section{CONCLUSION}

The Evaluation of construction baseline schedules aims to provide a high-quality project schedule. However, obtaining a project schedule free from technical errors remains a challenging to construction planners and schedulers.The result of having a high-quality schedule is achieving the desired project completion dates and avoid any disputes between the project parties which may be present due to the technical defects of the schedule.

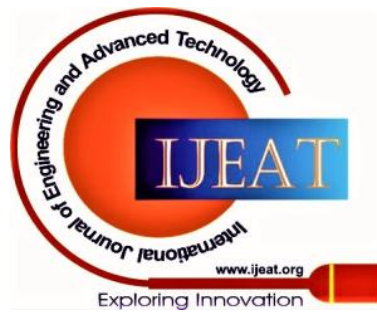


Many organizations had developed evaluation techniques for assessing the baseline schedules from different prospects and approaches. The aim of this study is to introduce an obvious technique for schedule evaluation. Which had been achieved by collecting all evaluation metrics and parameters related to the construction project baseline schedules from all published best recommended practices, then these metrics had been classified and filtered out through many steps and under some criteria. So that, it facilitate the schedule reviewing and evaluating process by presenting an obvious, arranged and classified evaluation metrics to let the schedule reviewer to list down all the schedule technical defects and convert them into clear comments before sending them for the contractor to take the right action towards the reviewer comments and having a schedule free of defects in result.

\section{REFERENCES}

1. J. M. Framinan and R. Leisten, Overview of Scheduling Systems, no. May 2016. 2014.

2. T. Seymour and S. Hussein, "The History Of Project Management," Int. J. Manag. Inf. Syst., vol. 18, no. 4, p. 233, 2014.

3. TMOGPI, "Critical path method, Turnaround Management for the Oil, Gas, and Process Industries.," Turnaround Manag. Oil, Gas, Process Ind., pp. 299-332, 2019.

4. J. W. Chinneck, "Chapter 11; PERT for Project Planning and Scheduling," Syst. Comput. Eng. Carlet. Univ., pp. 1-11, 2016.

5. A. Tomar and V. K. Bansal, "Scheduling of repetitive construction projects using geographic information systems: an integration of critical path method and line of balance," Asian J. Civ. Eng., vol. 20, no. 4, pp. 549-562, 2019.

6. FAO, "Overview of methods for baseline assessments; M\&E Technical Advisory Notes Series," M\&E Tech. Advis. Notes Ser., 2017.

7. N. Braimah, "Construction Delay Analysis Techniques-A Review of Application Issues and Improvement Needs," Buildings, vol. 3, no. 3, pp. 506-531, 2013.

8. K. P. L. Hoshino, "Forensic Schedule Analysis; AACE® International Recommended Practice No. 29R-03 FORENSIC," AACE® Int. Recomm. Pract. No. 29R-03 FORENSIC, no. 29, pp. 1-135, 2011.

9. [9] R. Winter, "Reviewing a Baseline Schedule," 2014.

10. GAO, "Schedule Assessment Guide," no. December, 2015.

11. DCMA, "Earned Value Management System ( EVMS ) Program Analysis Pamphlet ( PAP )," no. October, 2012.

12. NDIA, "Planning \& Scheduling Excellence Guide ( PASEG )," 2012.

13. C. W. Foster and A. Avalon, "Schedule Quality Assurance Procedures," AACE, no. 303, 2010.

14. PMI, "Practice Standard for Scheduling," Proj. Manag. Inst., p. 113, 2007.

15. NAVAIR, "Integrated Master Schedule (IMS) Guidebook," Nav. Air Syst. Command, no. February, 2010.

\section{AUTHORS PROFILE}

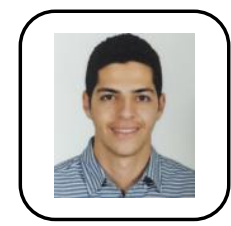

Amr A. Wael studied Civil Engineering at The British University in Egypt and was graduated in 2016. And currently, he is a student in the master's degree in Construction Management Program at The Arab Academy for Science and Technology.

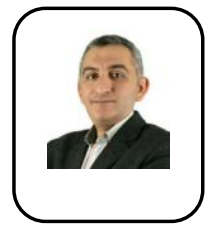

Ass. Prof. Ahmed Elyamanystudied B.Sc. in Civil Engineering at Zagazig University. He obtained the MSc in Construction Engineering from Zagazig University, Egypt.In 2010, he completed his Ph.D studies and graduated from North Dakota State University,USA.He is currently working as an Associate Professor in The British University in Egypt.

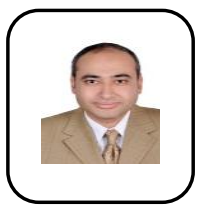

Ass. Prof. Ahmed Elhakeemstudied B.Sc. in Civil Engineering at Helwan University, Mataria and was graduated in 1996. He obtained the MSc in Construction Engineering and Management, University of Waterloo, Ontario, Canada, in 2002. Then he completed his PhD inConstruction Engineering and Management, University of Waterloo, Ontario, Canada in 2005.

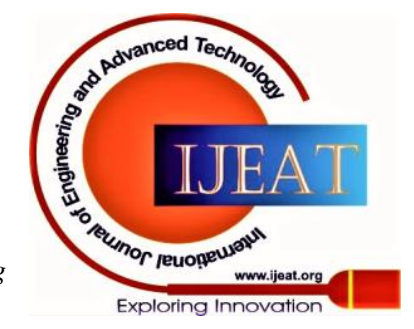

